\title{
Epidemiology, susceptibility, and risk factors for acquisition of MDR/XDR Gram-negative bacteria among kidney transplant recipients with urinary tract infections
}

This article was published in the following Dove Press journal:

Infection and Drug Resistance

\section{Xiuhong Yuan' \\ Taohua Liu² \\ DiWu ${ }^{3}$ \\ Qiquan Wan ${ }^{3}$}

'Psychosomatic Health Institute, the Third Xiangya Hospital of Central South University, Changsha, China; ${ }^{2}$ Clinical Medicine, Xiangya School of Medicine, Central South University, Changsha, China; ${ }^{3}$ Department of Transplant Surgery, the Third Xiangya Hospital of Central South University, Changsha, China
Correspondence: Qiquan Wan Department of Transplant Surgery, the Third Xiangya Hospital of Central South University, No I 38 Tongzipo Road,

Changsha 410013 , China

Tel/fax $+86731886 \mid 8312$

Email 13548685542@163.com
Background: Multiple drug resistant/extensively drug resistant (MDR/XDR) Gram-negative urinary tract infections (UTIs) represent a growing threat to kidney transplant recipients. This retrospective study aimed to assess the incidence and microbiological profile of MDR/XDR Gram-negative UTIs, to identify drug susceptibility of MDR/XDR bacteria, and to determine the potential risk factors for MDR/XDR UTIs in kidney recipients.

Materials and methods: During the study period, 1569 patients underwent consecutive kidney transplantation in two transplantation centers. We studied the demographics, clinical characteristics, and urine culture data from kidney recipients with MDR/XDR Gram-negative UTIs, and verified the risk factors associated with MDR/XDR infections.

Results: Eighty-one kidney recipients yielded 88 episodes of MDR/XDR Gram-negative UTIs with five patients $(6.2 \%)$ succumbing to all-cause in-hospital mortality. The most frequently isolated bacterium was Escherichia coli (62.5\%). Almost all MDR/XDR Gram-negative bacteria were resistant to first- and second-generation cephalosporin, and monocyclic beta-lactam. They were relatively sensitive to meropenem, amikacin, and tigecycline. As for the 12 XDR bacteria, all of them were resistant to meropenem and $25 \%$ of them were resistant to tigecycline. All XDR Acinetobacter baumannii and E. coli were susceptible to tigecycline. Nosocomial infection (odds ratio $[\mathrm{OR}]=11.429,95 \% \mathrm{CI}=1.311-99.625, P=0.027)$ was the only independent predictor of MDR/XDR Gram-negative UTIs. Non-fermenting bacterial infection $(\mathrm{OR}=20.161,95 \% \mathrm{CI}=$ $3.409-119.240, P=0.001)$, polycystic kidney disease $(\mathrm{OR}=39.871,95 \% \mathrm{CI}=1.979-803.384$, $P=0.016)$, and serum creatinine level $>1.5 \mathrm{mg} / \mathrm{dL}(\mathrm{OR}=8.688,95 \% \mathrm{CI}=1.354-55.747$, $P=0.023)$ were significantly different between XDR and MDR Gram-negative UTIs.

Conclusion: Meropenem, amikacin, and/or tigecycline can be prescribed for MDR/XDR Gram-negative infections. Tigecycline can also be prescribed for XDR A. baumannii and E. coli. Nosocomial infection was a risk factor for MDR/XDR Gram-negative UTIs, while XDR UTIs were associated with non-fermenting bacterial infection, polycystic kidney disease, and impaired renal function.

Keywords: kidney transplantation, bacteria, urinary tract infections, risk factors, MDR, XDR

\section{Introduction}

Urinary tract infection (UTI) ranks among the most common infectious complications among kidney transplant recipients, with up to $79 \%$ prevalence. ${ }^{1-4}$ It can pose a significant risk indirectly by leading to bacteremia, acute rejection, or cytomegalovirus infection. $^{5}$ 
An international meeting in 2012 proposed an interim standard definition of multiple drug resistant (MDR): "resistant to at least one agent in three or more antimicrobial categories" and of extensively drug resistant (XDR): "resistant to at least one agent in all but two or fewer antimicrobial categories". ${ }^{6}$ Magiorakos et al illustrated the interim standard definition of major MDR/XDR Gram-negative bacteria in detail, including Enterobacteriaceae, Pseudomonas aeruginosa, and Acinetobacter baumannii. MDR/XDR Pseudomonas putida and Burkholderia pseudomallei were defined as MDR/XDR $P$. aeruginosa in this study.

Although kidney recipients are particularly susceptible to MDR/XDR Gram-negative UTIs, which can lead to increased cost and longer duration of hospitalization, published data in this field among this population are limited. Adapting this standard definition of MDR, only two previous studies have been conducted so far to determine the frequency, risk factors, and clinical impact of recurrent UTIs, or to investigate the change of resistance in Enterobacteriaceae in kidney recipients. ${ }^{7,8}$ The risk factors for acquisition of MDR/XDR Gram-negative bacteria per se among kidney recipients with UTIs, up until now, have not been studied. Confirming these risk factors associated with MDR/XDR Gram-negative UTIs and preventing the first episode of UTI is of great importance. As this is the largest group of kidney transplant patients with UTIs due to MDR/XDR Gram-negative bacteria, being studied so far, goals of the present study were: 1) to analyze the incidence and microbiological profile of MDR/XDR Gramnegative bacteria, 2) to identify drug susceptibility of MDR/ XDR bacteria, and 3) the most important, to determine the potential risk factors for MDR/XDR UTIs. Thus, our findings can offer new insight into prevention of MDR/XDR UTIs among this population.

\section{Material and methods Study population}

We performed a retrospective cohort study reviewing the medical records of patients who received a kidney transplantation at the Third Xiangya Hospital of Central South University, Changsha and Zhongnan Hospital of Wuhan University, Wuhan, China from January 1, 2007 to March 31, 2017. All patients received second- or third-generation cephalosporins or semi-synthetic penicillins/beta-lactamase inhibitors perioperatively, usually for 5 to 7 days. A double-J ureteral stent was inserted routinely in each kidney recipient and removed after 3 to 6 weeks from transplantation. A urethral catheter was inserted in each patient perioperatively and removed from the 5 th to 7 th day postoperatively. The study protocol was approved by the Medical Ethics Committee of the Third Xiangya Hospital of Central South University and Zhongnan Hospital of Wuhan University. The ethics committee waived the need for written informed consent provided by participants due to the retrospective nature of the study. All patient data were analyzed in anonymity, and therefore, no additional informed consent was required.

\section{Study design and data collection}

A retrospective cohort study was performed to analyze features of MDR/XDR Gram-negative bacteria from urinary tract specimens of kidney recipients, including distribution, sensitivity to antibiotics, and risk factors for acquisition. Clinical characteristics and the data of urine culture as well as other laboratory data were collected.

Routine microbiological tests of urine and rectal swabs were not performed before transplantation in these patients. Urine cultures were systematically performed every day within the first 3 days after kidney transplantation, and then once a week during the first post-transplant month. Later, at each outpatient visit, a urine culture was performed when the presence of either clinical or laboratory symptoms suggested UTI. The follow-up time for every kidney recipient was at least 3 months after the onset of UTI. All patients were initially maintained on a triple immunosuppression (tacrolimus/cyclosporine + mycophenolate mofetil + glucocorticosteroids) and an additional agent of monoclonal (basiliximab) or polyclonal antibody (ATG) was prescribed in some patients.

We compared demographics and clinical data, as well as other laboratory data between patients with UTIs due to susceptible Gram-negative bacteria, also between patients suffering from MDR and XDR UTIs. This included age, sex, underlying kidney diseases, re-transplant, type of donor, body temperature, nosocomial origin, empirical antimicrobial use, duration of days between transplantation and the onset of UTI, type of immunosuppressants, the duration of meropenem and the other wide-spectrum antibiotic therapy within 1 month before UTIs, septic shock, and laboratory data like serum creatinine level.

\section{Definitions}

The diagnosis of UTI was made when the presence of symptoms or signs of urinary infection accompanied a quantitative bacterial count $\geq 10^{5} /$ high-power field in an appropriately collected urine specimen. ${ }^{9}$ Urosepsis was defined as simultaneous positive blood and urine cultures obtained with the isolation of the same bacterial strain. ${ }^{10}$ The UTIs were defined as polymicrobial if two or more different organisms were observed in 
urine cultures. ${ }^{11}$ Infection was defined to be early-onset when it occurred within the first 2 months after transplantation, and late-onset infection occurred beyond this time-point. ${ }^{12}$ Patients were diagnosed with UTI-related septic shock when their urine cultures were positive, in conjunction with dysfunction of at least one organ that could only be explained by hypoperfusion despite adequate fluid resuscitation. ${ }^{13}$ UTI-related mortality was considered when the death was related to clinical signs of active UTI without any other attributable cause. ${ }^{11}$

\section{Microbiologic studies}

Midstream urine samples or catheterized urine specimens of kidney recipients were obtained for bacterial culture. Species were identified using the Vitek-2 system (bioMérieux, Marcyl'Etoile, France). Antimicrobial susceptibility was determined by the Kirby-Bauer disk diffusion method, and the minimum inhibitory concentration was tested by agar dilution. Intermediate susceptibility was considered as having resistance.

\section{Statistical analysis}

Statistical analyses were executed with the statistical package SPSS for Windows, version 22.0 (IBM Corporation, Armonk, NY, USA). Results are listed as mean ( \pm SD) and median (1st-3rd quartile) for continuous variables with normal and skewed distributions, respectively. Continuous variables were compared using Student's unpaired $t$-test or the Mann-Whitney $U$ test. Categorical variables were compared by Pearson's $\chi^{2}$ test or Fisher's exact test when appropriate. Variables with a $P$-value $<0.05$ in the univariate analysis were introduced into the subsequent multivariate analysis based on forward stepwise logistic regression. Associations were given as odds ratios (ORs) with a 95\% CI. Statistical tests were bicaudate and a value of $P<0.05$ was considered to be statistically significant.

\section{Results}

A total of 1569 patients underwent consecutive kidney transplantation during the study period. In this group, 134 (8.5\%) patients experienced 153 culture-proven bacterial UTI episodes and 93 (5.9\%) patients yielded 101 episodes of Gram-negative infections, in which there were 16 episodes of non-fermenting bacteria, including ten episodes of A. baumannii, four of $P$. aeruginosa, and one each of P. putida and B. pseudomallei.

Eighty-one patients ( 32 males and 49 females, mean age $41.4 \pm 11.8$ years, range $10-65$ years) were diagnosed with 88 episodes of MDR/XDR Gram-negative UTIs, representing a $5.2 \%(81 / 1569)$ prevalence. There were six patients who suffered from urosepsis among these 81 patients with MDR/XDR Gram-negative UTIs, and one patient suffered from urosepsis among the remaining patients with non-MDR/ XDR UTIs. Demographic and clinical features of these 81 patients are illustrated in Table 1. All patients received grafts from donation after cardiac death or living related donors, apart from 16 who received them from deceased donors.

Table I Demographic and clinical characteristics of 81 kidney transplant patients diagnosed with urinary tract infections due to MDR/XDR Gram-negative bacteria

\begin{tabular}{|c|c|}
\hline Characteristics & Value \\
\hline Age, mean years $\pm S D$ & $41.4 \pm 11.8$ \\
\hline Sex, number of females, $n(\%)$ & $49(60.5)$ \\
\hline \multicolumn{2}{|l|}{ Underlying kidney diseases } \\
\hline Chronic glomerulonephritis & $62(76.5)$ \\
\hline Polycystic kidney disease & $3(3.7)$ \\
\hline Diabetic nephropathy & $2(2.5)$ \\
\hline Other/unknown & $14(17.3)$ \\
\hline Re-transplant & $4(4.9)$ \\
\hline Temperature of $38^{\circ} \mathrm{C}$ or greater, $\mathrm{n}(\%)$ & $25(30.9)$ \\
\hline $\begin{array}{l}\text { Median body temperature of }{ }^{\circ} \mathrm{C} \text { at infection onset } \\
\text { (IQR) }\end{array}$ & $37.1(36.6-38.4)$ \\
\hline Nosocomial origin, n (\%) & $37(45.7)$ \\
\hline Inappropriate empirical antimicrobial use, n (\%) & $32(39.5)$ \\
\hline Average duration of days between transplant and & $110(36.5-$ \\
\hline infection onset (IQR) & $1158)$ \\
\hline \multicolumn{2}{|l|}{ Type of organisms no. of cases (\%) } \\
\hline Monomicrobial & $74(91.4)$ \\
\hline Polymicrobial & $7(8.6)$ \\
\hline \multicolumn{2}{|l|}{ Drug resistance, $\mathrm{n}(\%)$} \\
\hline MDR & $70(86.4)$ \\
\hline XDR & II (I3.6) \\
\hline PDR & $0(0)$ \\
\hline \multicolumn{2}{|l|}{ Type of donor, no. of cases (\%) } \\
\hline Donation after cardiac death & $40(49.4)$ \\
\hline Living, related & $25(30.9)$ \\
\hline Deceased & $16(19.8)$ \\
\hline $\begin{array}{l}\text { Use of antilymphocyte or antithymocyte globulin, } \\
\text { no. of cases (\%) }\end{array}$ & $28(34.6)$ \\
\hline \multicolumn{2}{|l|}{$\begin{array}{l}\text { Patient immunosuppressant treatment, no. of } \\
\text { cases (\%) }\end{array}$} \\
\hline Tacrolimus & $66(81.5)$ \\
\hline Cyclosporine A & $14(17.3)$ \\
\hline None & $\mathrm{I}(\mathrm{I} .2)$ \\
\hline \multicolumn{2}{|l|}{ Laboratory variables from blood, no. of cases (\%) } \\
\hline WBC count $>15,000 / \mathrm{mm}^{3}$ & $14(17.3)$ \\
\hline Platelet count $<10,0000 / \mathrm{mm}^{3}$ & $7(8.6)$ \\
\hline Lymphocyte count $<500 / \mathrm{mm}^{3}$ & $12(14.8)$ \\
\hline Albumin level $<35 \mathrm{mg} / \mathrm{dL}$ & $16(19.8)$ \\
\hline Creatinine level $>1.5 \mathrm{mg} / \mathrm{dL}$ & $32(39.5)$ \\
\hline Septic shock at urinary tract infections onset & $3(3.7)$ \\
\hline All-cause in-hospital mortality & $5(6.2)$ \\
\hline Urinary tract infection-related mortality & $\mathrm{I}(1.2)$ \\
\hline
\end{tabular}

Abbreviations: IQR, interquartile range; MDR, multiple drug resistant; PDR, pandrug resistant; WBC, white blood cell; XDR, extensively drug resistant. 
Single UTI owing to MDR/XDR Gram-negative bacteria was demonstrated among $74(91.4 \%)$ patients, and seven $(8.6 \%)$ patients experienced two MDR/XDR Gram-negative infections. As for XDR Gram-negative infections, eleven patients experienced 12 episodes. No pandrug resistant (PDR) Gram-negative bacteria were isolated in the present study. Approximately $40 \%$ of cases with MDR/XDR Gram-negative UTIs had an increased serum creatinine level (>1.5 mg/dL). Three cases (3.7\%) of septic shock occurred at the onset of UTI. All-cause in-hospital mortality rate was $6.2 \%(5 / 81)$. One (1.2\%) patient with UTI due to an XDR Klebsiella pneumoniae progressed to $K$. pneumoniae bacteremia and died.

Among these $88 \mathrm{MDR} / \mathrm{XDR}$ Gram-negative bacteria recovered, the most frequently isolated pathogen was Escherichia coli $(62.5 \%, \mathrm{n}=55)$, followed by $K$. pneumoniae $(17 \%, \mathrm{n}=15)$, and $A$. baumannii $(10.2 \% ; \mathrm{n}=9)$ (Table 2). As presented in Table 3, MDR/XDR Gram-negative bacteria were highly resistant to first- and second-generation cephalosporin,

Table 2 Classification and percentage of 88 MDR/XDR bacteria isolated from urinary tract specimens in kidney transplant recipients

\begin{tabular}{lll}
\hline Microorganism & $\begin{array}{l}\text { Organisms } \\
(\mathbf{n}=\mathbf{8 8})\end{array}$ & Percentage \\
\hline Escherichia coli & 55 & 62.5 \\
Klebsiella pneumoniae & 15 & 17 \\
Acinetobacter baumannii & 9 & 10.2 \\
Pseudomonas aeruginosa & 2 & 2.3 \\
Enterobacter aerogenes & 2 & 2.3 \\
Proteus mirabilis & 2 & 2.3 \\
Enterobacter cloacae & 1 & 1.1 \\
Pseudomonas putida & 1 & 1.1 \\
Burkholderia pseudomallei & 1 & 1.1 \\
\hline
\end{tabular}

Abbreviations: MDR, multiple drug resistant; XDR, extensively drug resistant. and monocyclic beta-lactam, with the resistance rates of $96.6 \%, 96.6 \%$, and $93.2 \%$, respectively. On the other hand, they showed relative sensitivity to meropenem, amikacin, and tigecycline at resistance rates of $28.4 \%, 28.4 \%$, and $11.4 \%$, respectively. As for the 12 XDR Gram-negative bacteria, all of them were resistant to meropenem and piperacillin/tazobactam with $25 \%$ and $58.3 \%$ of them being resistant to tigecycline and cefoperazone/sulbactam, respectively. All XDR A. baumannii and $E$. coli were susceptible to tigecycline (Table 4).

As shown in Table 5, when compared with UTIs due to susceptible Gram-negative bacteria, the factors associated with MDR/XDR Gram-negative ones in univariate analysis were nosocomial infection and the use of wide-spectrum antibiotics for 5 days or more within 1 month before the onset of UTI. Nosocomial infection $(\mathrm{OR}=11.429,95 \% \mathrm{CI}=1.311-99.625$, $P=0.027$ ) was the only risk factor associated with MDR/XDR UTIs in multivariate analysis. No significant risk factors were determined among immunosuppressive drugs, including the use of tacrolimus and antilymphocyte or antithymocyte globulin.

The potential risk factors associated with XDR Gramnegative UTIs are outlined in Table 6 . When compared with MDR UTIs, factors associated with XDR ones in univariate analysis were polycystic kidney disease, nosocomial infection, early-onset infection, non-fermenting bacterial infection, the use of wide-spectrum antibiotics for 5 days or more within 1 month before the onset of UTI, the use of meropenem for 4 days or more within 1 month before the onset of UTI, and serum creatinine level $>1.5 \mathrm{mg} / \mathrm{dL}$. In multivariate analysis, the independent risk factors for XDR Gram-negative UTIs were polycystic kidney disease (OR $=39.871,95 \% \mathrm{CI}$ $=1.979-803.384, P=0.016)$, followed by non-fermenting bacterial infection $(\mathrm{OR}=20.161,95 \% \mathrm{CI}=3.409-119.240$,

Table 3 Resistance rates of 88 MDR/XDR Gram-negative bacteria to 12 antibiotics (n, [\%])

\begin{tabular}{|c|c|c|c|c|c|}
\hline Antimicrobial & $\begin{array}{l}\text { Escherichia } \\
\text { coli }(n=55)\end{array}$ & $\begin{array}{l}\text { Klebsiella } \\
\text { pneumoniae }(n=15)\end{array}$ & $\begin{array}{l}\text { Non-fermenting } \\
\text { bacteria }(n=13)\end{array}$ & $\begin{array}{l}\text { The other } \\
\text { Enterobacteria }(n=5)\end{array}$ & $\begin{array}{l}\text { Total drug resistance } \\
\text { rate }(\%)\end{array}$ \\
\hline TIG & $2(3.6)$ & $3(20)$ & $3(23.1)$ & $2(40)$ & 11.4 \\
\hline MEM & $9(16.4)$ & $3(20)$ & $12(92.3)$ & I (20) & 28.4 \\
\hline AN & $8(14.5)$ & $5(33.3)$ & II (84.6) & I (20) & 28.4 \\
\hline LVF & $35(63.6)$ & $9(60)$ & II (84.6) & $0(0)$ & 62.5 \\
\hline SXT & $35(63.6)$ & $10(66.7)$ & $13(100)$ & $4(80)$ & 70.5 \\
\hline PIT & $19(34.5)$ & $6(40)$ & $12(92.3)$ & $2(40)$ & 44.3 \\
\hline ATM & $54(98.2)$ & II (73.3) & $13(100)$ & $4(80)$ & 93.2 \\
\hline CZO & $54(98.2)$ & $13(86.7)$ & $13(100)$ & $5(100)$ & 96.6 \\
\hline CXM & $54(98.2)$ & $13(86.7)$ & $13(100)$ & $5(100)$ & 96.6 \\
\hline CAZ & $46(83.6)$ & II (73.3) & $12(92.3)$ & $3(60)$ & 81.8 \\
\hline FEP & $48(87.3)$ & $10(66.7)$ & $12(92.3)$ & $4(80)$ & 84.1 \\
\hline CFS & $30(54.5)$ & $5(33.3)$ & $3(23.1)$ & $3(60)$ & 46.6 \\
\hline
\end{tabular}

Abbreviations: AN, amikacin; ATM, aztreonam; CAZ, ceftazidime; CFS, cefoperazone/sulbactam; CXM, cefuroxime; CZO, cefazolin; FEP, cefepime; LVF, levofloxacin; MDR, multiple drug resistant; MEM, meropenem; PIT, piperacillin/tazobactam; SXT, trimethoprim/sulfamethoxazole; TIG, tigecycline; XDR, extensively drug resistant. 
Table 4 Resistance rates of 12 XDR Gram-negative bacteria to five antibiotics that MDR/XDR bacteria remain relatively susceptible to $(\mathrm{n},[\%])$

\begin{tabular}{llllll}
\hline Antimicrobial & $\begin{array}{l}\text { Acinetobacter } \\
\text { baumannii }(\mathbf{n = 4})\end{array}$ & $\begin{array}{l}\text { Escherichia } \\
\text { coli }(\mathbf{n = 3})\end{array}$ & $\begin{array}{l}\text { Klebsiella } \\
\text { pneumoniae }(\mathbf{n}=\mathbf{2})\end{array}$ & $\begin{array}{l}\text { Pseudomonas } \\
\text { spp. }(\mathbf{n = 3})^{\mathrm{a}, \mathrm{b}}\end{array}$ & $\begin{array}{l}\text { Total drug } \\
\text { resistance rate (\%) }\end{array}$ \\
\hline TIG & $0(0)$ & $0(0)$ & $1(50)$ & $2(66.7)$ & 25 \\
MEM & $4(100)$ & $3(100)$ & $2(100)$ & $3(100)$ & 100 \\
AN & $4(100)$ & $1(33.3)$ & $1(50)$ & $3(100)$ & 75 \\
PIT & $4(100)$ & $3(100)$ & $2(100)$ & $3(100)$ & 100 \\
CFS & $2(50)$ & $2(66.7)$ & $2(100)$ & $1(33.3)$ & 58.3 \\
\hline
\end{tabular}

Notes: ${ }^{a}$ Including one isolate of Pseudomonas putida, one Burkholderia pseudomallei, and one Pseudomonas aeruginosa wherein Burkholderia pseudomallei is susceptible to TIG and Pseudomonas putida is resistant to CFS. ${ }^{b} \mathrm{P}$. aeruginosa is intrinsically resistant to tigecycline.

Abbreviations: AN, amikacin; CFS, cefoperazone/sulbactam; MDR, multiple drug resistant; MEM, meropenem; PIT, piperacillin/tazobactam; TIG, tigecycline; XDR, extensively drug resistant.

Table 5 Univariate and multivariate analysis of risk factors associated with the occurrence of MDR/XDR Gram-negative UTls

\begin{tabular}{|c|c|c|c|c|}
\hline Characteristics & $\begin{array}{l}\text { MDR/ } \\
\text { XDR UTIs }\end{array}$ & $\begin{array}{l}\text { Non-MDR/ } \\
\text { XDR UTIs }\end{array}$ & $P$-value ${ }^{\wedge}$ & OR $(95 \% \mathrm{Cl})$ \\
\hline Total, n (\%) & $81(87.1)$ & $12(12.9)$ & & \\
\hline \multicolumn{5}{|l|}{ Univariate analysis, n (\%) } \\
\hline Age $\geq 40$ years & $49(60.5)$ & $7(58.3)$ & 0.887 & $0.613(0.065-5.808)$ \\
\hline Male sex & $32(39.5)$ & $4(33.3)$ & 0.682 & $4.893(0.219-109.073)$ \\
\hline Re-transplant & $4(4.9)$ & I (8.3) & 0.627 & $0.129(0.003-5.266)$ \\
\hline Polycystic kidney disease & $3(3.7)$ & $0(0)$ & 0.498 & $0.423(0.040-4.434)$ \\
\hline Temperature $\geq 38^{\circ} \mathrm{C}$ & $25(30.9)$ & $5(4 \mid .7)$ & 0.455 & $0.279(0.024-3.183)$ \\
\hline Nosocomial infection & $37(45.7)$ & I (8.3) & $0.014^{*}$ & $9.250(1.140-75.031)$ \\
\hline Graft from $D C D$ donors & $16(19.8)$ & $3(25)$ & 0.114 & $1.979(0.227-17.235)$ \\
\hline Early-onset infection & $25(30.9)$ & $3(25)$ & 0.416 & $0.796(0.033-19.297)$ \\
\hline Non-fermenting bacteria & $12(14.8)$ & $3(25)$ & 0.371 & $0.037(0.001-1.569)$ \\
\hline Use of antilymphocyte or antithymocyte globulin & $28(34.6)$ & $3(25)$ & 0.512 & $1.508(0.200-11.358)$ \\
\hline Use of tacrolimus & $66(81.5)$ & $8(66.7)$ & 0.235 & $2.134(0.207-22.018)$ \\
\hline Use of wide-spectrum antibiotics for 5 days or more within & $49(60.5)$ & $3(25)$ & $0.021 *$ & $4.594(1.155-18.269)$ \\
\hline \multicolumn{5}{|l|}{ I month before UTIs } \\
\hline Use of meropenem for 4 days or more within I month before UTls & II (13.4) & $0(0)$ & 0.21 & $1.729(0.203-14.744)$ \\
\hline Septic shock & $3(3.7)$ & I (8.3) & 0.498 & $0.423(0.040-4.434)$ \\
\hline WBC count $>15,000 / \mathrm{mm}^{3}$ & $14(17.3)$ & $2(16.7)$ & 0.958 & $2.029(0.106-38.865)$ \\
\hline Platelet count $<10,0000 / \mathrm{mm}^{3}$ & $7(8.6)$ & $3(25)$ & 0.088 & $0.110(0.002-5.634)$ \\
\hline Lymphocyte count $<500 / \mathrm{mm}^{3}$ & $12(14.8)$ & $3(25)$ & 0.371 & $0.07 \mid(0.002-2.219)$ \\
\hline Albumin level $<35 \mathrm{mg} / \mathrm{dL}$ & $16(19.8)$ & $2(16.7)$ & 0.801 & $\mid 2.439(0.35 \mid-440.472)$ \\
\hline Creatinine level $>1.5 \mathrm{mg} / \mathrm{dL}$ & $32(39.5)$ & $2(16.7)$ & 0.125 & $0.897(0.055-14.676)$ \\
\hline \multicolumn{5}{|l|}{ Multivariate analysis } \\
\hline Nosocomial infection & & & $0.027 *$ & II.429 (1.31 I-99.625) \\
\hline
\end{tabular}

Notes: ${ }^{P}$-value from Pearson's $\chi^{2}$ test or Fisher's exact test in univariate analysis and from multiple logistic regression in multivariate analysis. ${ }^{*}$ The $P$-values are statistically significant.

Abbreviations: DCD, donation after cardiac death; MDR, multiple drug resistant; UTIs, urinary tract infections; WBC, white blood cell; XDR, extensively drug resistant.

$P=0.001)$, and creatinine level $>1.5 \mathrm{mg} / \mathrm{dL}(\mathrm{OR}=8.688$, $95 \% \mathrm{CI}=1.354-55.747, P=0.023)$.

\section{Discussion}

UTIs, mainly bacterial, are a common infectious complication and remain one of the risk factors for graft loss and patient death in kidney recipients. ${ }^{1,3}$ Extended spectrum beta-lactamase (ESBL)-producing Enterobacteriaceae is associated with UTIs and recurrent UTIs, which may cause subsequent impaired renal function or even graft loss among kidney recipients. ${ }^{4,7,9,14}$ However, MDR/XDR Gram-negative bacteria, a growing threat to transplant populations, have not been well-studied in kidney recipients with UTIs since the interim standard definition of MDR/XDR was proposed. ${ }^{6}$

UTIs were more common in female kidney recipients. Several other papers confirmed female sex to be the strongest risk factor for various types of UTIs. ${ }^{15,16}$ In our present study, however, female sex did not increase the risk for MDR/XDR UTIs when compared with UTIs due to susceptible Gramnegative bacteria. 
Table 6 Univariate and multivariate analysis of risk factors associated with the occurrence of XDR Gram-negative UTIs

\begin{tabular}{|c|c|c|c|c|}
\hline Characteristics & XDR UTIs & MDR UTIs & $P$-value ${ }^{\wedge}$ & OR $(95 \% \mathrm{Cl})$ \\
\hline Total, n (\%) & II (I3.6) & $70(86.4)$ & & \\
\hline \multicolumn{5}{|l|}{ Univariate analysis, n (\%) } \\
\hline Age $\geq 40$ years & $4(36.4)$ & $45(64.3)$ & 0.078 & $0.209(0.027-1.630)$ \\
\hline Male sex & $6(54.5)$ & $26(37.1)$ & 0.272 & $0.637(0.070-5.782)$ \\
\hline Re-transplant & $0(0)$ & $4(36.4)$ & 0.416 & $2.566(0.022-283.083)$ \\
\hline Polycystic kidney disease & $2(18.2)$ & I ( $(.4)$ & $0.006^{*}$ & I5.333 (1.260-186.600) \\
\hline Temperature $\geq 38^{\circ} \mathrm{C}$ & $3(27.3)$ & $22(31.4)$ & 0.781 & I. $108(0.15 \mathrm{I}-8.140)$ \\
\hline Nosocomial infection & $9(81.8)$ & $28(40)$ & $0.01 *$ & $6.750(1.356-33.603)$ \\
\hline Graft from DCD donors & $7(63.6)$ & $33(47.1)$ & 0.309 & $0.848(0.129-5.567)$ \\
\hline Early-onset infection & $8(72.7)$ & $22(31.4)$ & $0.008^{*}$ & $5.818(|.407-24.06|)$ \\
\hline Non-fermenting bacteria infection & $6(54.5)$ & $6(8.6)$ & $<0.001 *$ & II.627 (I.442-93.755) \\
\hline Use of antilymphocyte or antithymocyte globulin & $3(27.3)$ & $25(35.7)$ & 0.584 & $0.033(0.00 I-I .07 I)$ \\
\hline Use of tacrolimus & $9(81.8)$ & $57(81.4)$ & 0.975 & $7.948(0.365-172.903)$ \\
\hline Use of wide-spectrum antibiotics for 5 days or more within & II (100) & $38(54.3)$ & $0.026^{*}$ & $8.421(1.022-69.371)$ \\
\hline \multicolumn{5}{|l|}{ I month before UTIs } \\
\hline Use of meropenem for 4 days or more within & $4(36.4)$ & $7(10)$ & $0.018^{*}$ & $5.143(1.200-22.049)$ \\
\hline \multicolumn{5}{|l|}{ I month before UTIs } \\
\hline Septic shock & I (9.1) & $2(2.9)$ & 0.309 & $3.400(0.282-4 I .03 I)$ \\
\hline WBC count $>15,000 / \mathrm{mm}^{3}$ & $I(9.1)$ & $13(18.6)$ & 0.439 & $0.438(0.05 I-3.734)$ \\
\hline Platelet count $<10,0000 / \mathrm{mm}^{3}$ & $2(18.2)$ & $5(7.1)$ & 0.226 & $4.630(0.298-71.833)$ \\
\hline Lymphocyte count $<500 / \mathrm{mm}^{3}$ & $2(18.2)$ & $10(14.3)$ & 0.735 & $1.786(0.154-20.724)$ \\
\hline Albumin level $<35 \mathrm{mg} / \mathrm{dL}$ & I (9.I) & $15(21.4)$ & 0.339 & $0.367(0.043-3.096)$ \\
\hline Creatinine level $>1.5 \mathrm{mg} / \mathrm{dL}$ & $9(81.8)$ & $23(32.9)$ & $0.002^{*}$ & $7.474(1.053-53.022)$ \\
\hline \multicolumn{5}{|l|}{ Multivariate analysis } \\
\hline Creatinine $>1.5$ mg/dL & & & $0.023^{*}$ & $8.688(1.354-55.747)$ \\
\hline Non-fermenting bacteria & & & $0.00 I^{*}$ & 20.161 (3.409-119.240) \\
\hline Polycystic kidney disease & & & $0.016^{*}$ & 39.871 (1.979-803.384) \\
\hline
\end{tabular}

Notes: ${ }^{\wedge}$-value from Pearson's $\chi^{2}$ test or Fisher's exact test in univariate analysis and from multiple logistic regression in multivariate analysis. ${ }^{*}$ The $P$-values are statistically significant.

Abbreviations: DCD, donation after cardiac death; MDR, multiple drug resistant; UTIs, urinary tract infections; WBC, white blood cell; XDR, extensively drug resistant.

A total of 153 culture-proven bacterial UTI episodes were verified during the study period and the episodes of Gram-negative infections accounted for $66 \%(n=101)$ of all bacterial UTI episodes. Our findings were consistent with a previous study claiming that Gram-negative bacteria led to $70 \%$ of UTIs among kidney recipients. ${ }^{16}$ Furthermore, the most frequent MDR/XDR Gram-negative organisms obtained from urinary tract specimens were E. coli $(62.5 \%)$, consistent with earlier studies reporting $E$. coli to be the major pathogen in kidney recipients with UTIs. ${ }^{14,15,17}$

Several prior studies demonstrated that MDR isolates were responsible for up to $69.1 \%$ of all organisms leading to symptomatic UTIs in kidney recipients. ${ }^{8,15,17}$ Although MDR/XDR Gram-negative UTI-related mortality was as low as $1.2 \%(1 / 81)$, we found the majority $(87.1 \%, \mathrm{n}=$ 81) of Gram-negative bacteria causing UTIs were MDR/ XDR. The finding of low UTI-related mortality is extremely similar to previous studies reporting that no mortality associated with UTIs was observed in kidney recipients with UTIs. ${ }^{10,18}$ However, Chuang et al reported 4.7\% (10/213) of kidney recipients with UTIs died. ${ }^{19}$ We also found allcause in-hospital mortality in kidney recipients with MDR/ XDR Gram-negative UTIs was at a relatively high level of $6.2 \%$, in line with a recent study reporting that UTI alone predicted an increased first-year mortality rate of $41 \%$ in kidney recipients. ${ }^{20} \mathrm{XDR}$ bacteria accounted for $13.6 \%$ of all MDR/XDR Gram-negative bacteria recovered from kidney recipients with UTIs, which represents a therapeutic problem. Fortunately, no PDR Gram-negative bacterium was found during the present study.

The drug susceptibility test showed the highest resistance rate (>90\%) of MDR/XDR Gram-negative bacteria to first- and second-generation cephalosporins and monocyclic beta-lactam, and relatively high resistance rate $(>80 \%)$ to third- and fourth-generation cephalosporins. More than $90 \%$ of MDR/XDR non-fermenting bacteria were resistant to meropenem. Fortunately, only $11.4 \%$ of all MDR/XDR bacteria were resistant to tigecycline. After eliminating the influence of $P$ a aeruginosa on the drug resistance rate, only $9.1 \%$ of the other MDR/XDR bacteria were resistant 
to tigecycline, as $P$. aeruginosa is intrinsically resistant to tigecycline. As for the 12 XDR Gram-negative bacteria, all of them were resistant to meropenem and piperacillin/tazobactam. A large amount of them (58.3\%) were cefoperazone/ sulbactam resistant, but only $25 \%$ of them were tigecycline resistant. Furthermore, all XDR A. baumannii and E. coli were tigecycline sensitive. After eliminating the influence of P. aeruginosa, only $16.7 \%$ of the other XDR bacteria were resistant to tigecycline.

Combination therapies of two to three different antibiotic classes (beta-lactam + aminoglycoside \pm fluoroquinolone) for 10-14 days for the treatment of XDR P. aeruginosa infections have been recommended by a previous study. ${ }^{21}$ For XDR A. baumannii, previous studies suggested that colistincarbapenem or colistin-sulbactam combinations may result in improved clinical responses and survival in transplant recipients. ${ }^{22-24}$ Bader et al suggested that aminoglycosides, colistin, and tigecycline were considered alternatives in MDR Gramnegative UTIs in patients with limited therapeutic options. ${ }^{25}$ According to our results of antibiotic susceptibility profile, as tigecycline, meropenem, and amikacin were among the most active drugs against MDR/XDR Gram-negative bacteria, we could suggest monotherapy or combination therapy of these three antibiotics in kidney recipients with UTIs owing to MDR/XDR bacteria. And for XDR Gram-negative bacteria, a combination of tigecycline and cefoperazone/sulbactam may be an effective treatment option.

To improve the outcome of kidney transplantation, several studies have investigated the risk factors for the first episode of UTI/recurrent UTIs. The risk factors for the first episode of UTIs were age, use of grafts from deceased donors, glomerulonephritis, re-transplant, reflux kidney disease, cytomegalovirus disease, recurrent UTI prior to transplant, use of azathioprine, presence of urological abnormalities, acute rejection, and underlying diabetes mellitus. ${ }^{19,26-29}$ Whereas the variables associated with a higher risk of recurrent UTIs included a first or second episode of UTI caused by MDR bacteria, age $>60$ years, and reoperation. ${ }^{7}$ The risk factors associated with UTIs caused by ESBL-producing bacteria in kidney transplant patients were also investigated, which included older age, longer time from kidney transplantation to the first positive urine culture, previous episodes of UTI, and reoperations. ${ }^{4,30}$

Immunosuppression and selective antibiotic pressure are risk factors for the emergence of antibiotic resistant uropathogens. ${ }^{15,31}$ After analyzing five studies of urinary tract bacteria (14,348 participants), Costelloe et al revealed that the pooled OR for resistance was 2.5 ( $95 \%$ CI 2.1 to
2.9 ) within 2 months of antibiotic treatment and 1.33 (1.2 to 1.5) within 12 months. ${ }^{32}$ However, we failed to identify the association between the use of immunosuppressants and the predominance of MDR/XDR Gram-negative uropathogen. We found that the use of wide-spectrum antibiotics for 5 days or more within 1 month before UTIs was associated with more frequent MDR/XDR UTIs in the univariate analysis, but this variable did not reach statistical significance in the multivariate analyses. Although the use of wide-spectrum antibiotics for 5 days or more and meropenem for 4 days or more within 1 month before UTIs were associated with the predominance of XDR UTIs, it failed to remain in our final multivariate logistic regression model. However, we found that nosocomial infection, which also represents selective antibiotic pressure, was a risk factor for MDR/XDR UTIs, in line with previous studies which claimed that one of the independent risk factors for MDR/XDR P. aeruginosa BSIs in transplant recipients was hospital acquisition. ${ }^{33,34}$

UTIs were more common in kidney recipients with impaired function. ${ }^{17}$ Approximately $40 \%$ of cases with MDR/ XDR Gram-negative UTIs had an increased serum creatinine level $(>1.5 \mathrm{mg} / \mathrm{dL})$ in our present study. Munoz reported serum creatinine levels $>2 \mathrm{mg} / \mathrm{dL}$ to be a post-transplant risk factor of having a delayed UTI ( $>6$ months postprocedure). ${ }^{35} \mathrm{Wu}$ et al found that baseline serum creatinine level $>1.3 \mathrm{mg} / \mathrm{dL}$ before first UTI represented an independent predictor of UTI with concomitant bacteremia. ${ }^{36} \mathrm{We}$ also found that elevated serum creatine level was associated with XDR Gram-negative UTIs in comparison with MDR ones. Gołezbiewska et al thought that the patients with initially worse renal graft function may be more prone to develop UTIs. ${ }^{37}$ The possible explanations for this phenomenon include a need for longer hospitalization, the requirement of prolonged venous catheterization, more antibiotic exposure, and greater impaired immunity. ${ }^{31,36}$

XDR non-fermenters are progressively growing as a cause of infection in solid organ transplant patients, and represent a global threat. ${ }^{38}$ We found that $43.8 \%(7 / 16)$ of all nonfermenting bacteria were XDR and that a risk factor associated with XDR UTIs was non-fermenting bacterial infection. Our findings herein agree with two previous studies claiming that $63 \%$ each of $P$. aeruginos $a$ and non-fermenting bacteria causing bacteremias were XDR P. aeruginosa and XDR nonfermenting bacteria in solid organ transplant recipients. ${ }^{34,39}$

Another risk factor we found in the present study for XDR Gram-negative UTIs was polycystic kidney disease, one of the risk factors for UTIs confirmed by a prior study ${ }^{35}$ Although routine pre-transplantation nephrectomy 
is not recommended, bilateral native nephrectomy might be indicated if the native polycystic kidneys act as a "reservoir" for infection. ${ }^{35}$

To the best of our knowledge, the present study is the first to report the incidence, strains, susceptibility, and risk factors for acquisition of MDR/XDR Gram-negative bacteria isolated from kidney recipients with UTIs, since the interim standard definition of MDR/XDR was proposed.

Study limitations include the retrospective nature of the study. The wide CIs in this analysis reflect the relatively small numbers of XDR and susceptible Gram-negative bacteria, with a consequent loss of statistical power. Also, urine cultures were not routinely performed beyond the first post-transplant month and as a result, the actual prevalence of UTIs might have been underestimated.

In conclusion, this study confirmed that MDR/XDR bacteria were responsible for the majority of pathogens recovered from kidney recipients with Gram-negative UTIs. XDR bacteria accounted for $13.6 \%$ of all MDR/XDR Gramnegative bacteria and represented a severe therapeutic issue. The drug resistance of Gram-negative bacteria to commonly used antibiotics was intensely severe since $90 \%$ of MDR non-fermenting bacteria and all XDR Gram-negative bacteria were resistant to meropenem. Nosocomial infection was associated with MDR/XDR Gram-negative UTIs among kidney recipients. The independent predictors of XDR Gramnegative UTIs included non-fermenting bacterial infection, polycystic kidney disease, and elevated creatinine level. However, the reader should bear in mind that this study was based on retrospective data with a limited number of kidney recipients with XDR or susceptible Gram-negative UTIs, thus, the findings need to be further verified.

\section{Acknowledgment}

This work was supported by grant 20170311 from the New Xiangya Talent Project of the Third Xiangya Hospital of Central South University.

\section{Disclosure}

The authors report no conflicts of interest in this work.

\section{References}

1. Leylabadlo HE, Kafil HS, Yousefi M, Aghazadeh M, Asgharzadeh M. Persistent infection with metallo-beta-lactamase and extended spectrum $\beta$-lactamase producer Morganella morganii in a patient with urinary tract infection after kidney transplantation. J Nat Sci Biol Med. 2016;7(2):179-181.

2. Yabanoğlu H, Alışkan HE, Çalış̧kan K, et al. Early infections in renal transplant recipients: incidence, risk factors, and causative microorganisms. Exp Clin Transplant. 2015;13 Suppl 3:11-14.
3. Espinar MJ, Miranda IM, Costa-de-Oliveira S, et al. Urinary tract infections in kidney transplant patients due to Escherichia coli and Klebsiella pneumoniae-producing extended-spectrum $\beta$-lactamases: risk factors and molecular epidemiology. PLoS One. 2015;10(8):e0134737.

4. Pilmis B, Scemla A, Join-Lambert O, et al. ESBL-producing enterobacteriaceae-related urinary tract infections in kidney transplant recipients: incidence and risk factors for recurrence. Infect Dis (Lond). 2015;47(10):714-718.

5. Silva M Jr, Marra AR, Pereira CA, Medina-Pestana JO, Camargo LF. Bloodstream infection after kidney transplantation: epidemiology, microbiology, associated risk factors, and outcome. Transplantation. 2010;90(5):581-587.

6. Magiorakos AP, Srinivasan A, Carey RB, et al. Multidrug-resistant, extensively drug-resistant and pandrug-resistant bacteria: an international expert proposal for interim standard definitions for acquired resistance. Clin Microbiol Infect. 2012;18(3):268-281.

7. Bodro M, Sanclemente G, Lipperheide I, et al. Impact of antibiotic resistance on the development of recurrent and relapsing symptomatic urinary tract infection in kidney recipients. Am J Transplant. 2015;15(4):1021-1027.

8. Origüen J, Fernández-Ruiz M, López-Medrano F, et al. Progressive increase of resistance in Enterobacteriaceae urinary isolates from kidney transplant recipients over the past decade: narrowing of the therapeutic options. Transpl Infect Dis. 2016;18(4):575-584.

9. Silva C, Afonso N, Macario F, Alves R, Mota A. Recurrent urinary tract infections in kidney transplant recipients. Transplant Proc. 2013;45(3): 1092-1095.

10. Gołębiewska J, Tarasewicz A, Dębska-Ślizień A, Rutkowski B. Klebsiella spp urinary tract infections during first year after renal transplantation. Transplant Proc. 2014;46(8):2748-2751.

11. Wan Q, Ye Q, Zhou J. Mortality predictors of bloodstream infections in solid-organ transplant recipients. Exp Clin Transplant. 2013; 11(3):211-214.

12. Lee SO, Kang SH, Abdel-Massih RC, Brown RA, Razonable RR. Spectrum of early-onset and late-onset bacteremias after liver transplantation: implications for management. Liver Transpl. 2011;17(6):733-741.

13. Levy MM, Fink MP, Marshall JC, et al. 2001 SCCM/ESICM/ACCP/ ATS/SIS International Sepsis Definitions Conference. Intensive Care Med. 2003;29(4):530-538.

14. Lim JH, Cho JH, Lee JH, et al. Risk factors for recurrent urinary tract infection in kidney transplant recipients. Transplant Proc. 2013;45(4):1584-1589.

15. Kotagiri P, Chembolli D, Ryan J, Hughes PD, Toussaint ND. Urinary tract infections in the first year post-kidney transplantation: potential benefits of treating asymptomatic bacteriuria. Transplant Proc. 2017;49(9):2070-2075.

16. Lee JR, Bang H, Dadhania D, et al. Independent risk factors for urinary tract infection and for subsequent bacteremia or acute cellular rejection: a single-center report of 1166 kidney allograft recipients. Transplantation. 2013;96(8):732-738.

17. Gozdowska J, Czerwinska M, Chabros L, et al. Urinary tract infections in kidney transplant recipients hospitalized at a transplantation and nephrology ward: 1-year follow-up. Transplant Proc. 2016;48(5): $1580-1589$.

18. Kosmadakis G, Daikos GL, Pavlopoulou ID, et al. Infectious complications in the first year post renal transplantation. Transplant Proc. 2013;45(4):1579-1583.

19. Chuang P, Parikh CR, Langone A. Urinary tract infections after renal transplantation: a retrospective review at two US transplant centers. Clin Transplant. 2005;19(2):230-235.

20. Naik AS, Dharnidharka VR, Schnitzler MA, et al. Clinical and economic consequences of first-year urinary tract infections, sepsis and pneumonia in contemporary kidney transplantation practice. Transpl Int. 2016;29(2):241-252.

21. Lim TP, Lee W, Tan TY, et al. Effective antibiotics in combination against extreme drug-resistant Pseudomonas aeruginosa with decreased susceptibility to polymyxin B. PLoS One. 2011;6(12):e28177. 
22. Shields RK, Kwak EJ, Potoski BA, et al. High mortality rates among solid organ transplant recipients infected with extensively drug-resistant Acinetobacter baumannii: using in vitro antibiotic combination testing to identify the combination of a carbapenem and colistin as an effective treatment regimen. Diagn Microbiol Infect Dis. 2011;70(2):246-252.

23. Shields RK, Clancy CJ, Gillis LM, et al. Epidemiology, clinical characteristics and outcomes of extensively drug-resistant Acinetobacterbaumannii infections among solid organ transplant recipients. PLoS One. 2012;7(12): e52349.

24. Metan G, Pala Ç, Kaynar L, Cevahir F, Alp E. A nightmare for haematology clinics: extensively drug-resistant (XDR) Acinetobacter baumannii. Infez Med. 2014;22(4):277-282.

25. Bader MS, Loeb M, Brooks AA. An update on the management of urinary tract infections in the era of antimicrobial resistance. Postgrad Med. 2017;129(2):242-258.

26. Fiorante S, Fernández-Ruiz M, López-Medrano F, et al. Acute graft pyelonephritis in renal transplant recipients: incidence, risk factors and long-term outcome. Nephrol Dial Transplant. 2011;26(3):1065-1073.

27. Giral M, Pascuariello G, Karam G, et al. Acute graft pyelonephritis and long-term kidney allograft outcome. Kidney Int. 2002;61(5):1880-1886.

28. Ariza-Heredia EJ, Beam EN, Lesnick TG, et al. Urinary tract infections in kidney transplant recipients: role of gender, urologic abnormalities, and antimicrobial prophylaxis. Ann Transplant. 2013;18:195-204.

29. Sorto R, Irizar SS, Delgadillo G, et al. Risk factors for urinary tract infections during the first year after kidney transplantation. Transplant Proc. 2010;42(1):280-281.

30. Pinheiro HS, Mituiassu AM, Carminatti M, Braga AM, Bastos MG. Urinary tract infection caused by extended spectrum beta-lactamaseproducing bacteria in kidney transplant patients. Transplant Proc. 2010;42(2):486-487.
31. Linares L, Cervera C, Cofán F, et al. Risk factors for infection with extended-spectrum and $\mathrm{AmpC}$ beta-lactamase-producing gramnegative rods in renal transplantation. Am J Transplant. 2008;8(5): 1000-1005.

32. Costelloe C, Metcalfe C, Lovering A, Mant D, Hay AD. Effect of antibiotic prescribing in primary care on antimicrobial resistance in individual patients: systematic review and meta-analysis. BMJ. 2010; 340:c2096.

33. Johnson LE, D'Agata EM, Paterson DL, et al. Pseudomonas aeruginosa bacteremia over a 10-year period: multidrug resistance and outcomes in transplant recipients. Transpl Infect Dis. 2009;11(3):227-234.

34. Bodro M, Sabé N, Tubau F, et al. Extensively drug-resistant Pseudomonas aeruginosa bacteremia in solid organ transplant recipients. Transplantation. 2015;99(3):616-622.

35. Munoz P. Management of urinary tract infections and lymphocele in renal transplant recipients. Clin Infect Dis. 2001;33 Suppl 1:S53-57.

36. Wu SW, Liu KS, Lin CK, et al. Community-acquired urinary tract infection in kidney transplantation: risk factors for bacteremia and recurrent infection. J Formos Med Assoc. 2013;112(3):138-143.

37. Gołębiewska JE, Dębska-Ślizień A, Rutkowski B. Urinary tract infections during the first year after renal transplantation: one center's experience and a review of the literature. Clin Transplant. 2014;28(11): 1263-1270.

38. Cervera C, van Delden C, Gavaldà J, et al. Multidrug-resistant bacteria in solid organ transplant recipients. Clin Microbiol Infect. 2014;20 Suppl 7:49-73.

39. Sganga G, Spanu T, Bianco G, et al. Bacterial bloodstream infections in liver transplantation: Etiologic agents and antimicrobial susceptibility profiles. Transplant Proc. 2012;44(7):1973-1976.
Infection and Drug Resistance

\section{Publish your work in this journal}

Infection and Drug Resistance is an international, peer-reviewed openaccess journal that focuses on the optimal treatment of infection (bacterial, fungal and viral) and the development and institution of preventive strategies to minimize the development and spread of resistance. The journal is specifically concerned with the epidemiology of antibiotic

\section{Dovepress}

resistance and the mechanisms of resistance development and diffusion in both hospitals and the community. The manuscript management system is completely online and includes a very quick and fair peerreview system, which is all easy to use. Visit http://www.dovepress.com/ testimonials.php to read real quotes from published authors. 